\title{
Metastatic Gallbladder Carcinoma
}

National Cancer Institute

\section{Source}

National Cancer Institute. Metastatic Gallbladder Carcinoma. NCI Thesaurus. Code C162754.

A gallbladder carcinoma that has spread from the original site of growth to other anatomic sites. 